\title{
Divergent Pathways Mediate the Induction of ANF Transgenes in Neonatal and Hypertrophic Ventricular Myocardium
}

Kirk U. Knowlton, ${ }^{\star}$ Howard A. Rockman, ${ }^{\star}$ Mahmoud Itani, ${ }^{\star}$ Andre Vovan, ${ }^{\star}$ Christine E. Seidman, ${ }^{\ddagger}$ and Kenneth R. Chien *Department of Medicine, Center for Molecular Genetics, and the American Heart Association-Bugher Foundation Center for Molecular Biology, University of California, San Diego, School of Medicine, La Jolla, California 92093; and ${ }^{\ddagger}$ Department of Medicine,

Brigham and Women's Hospital, Harvard Medical School, Boston, Massachusetts 02163

\begin{abstract}
To determine whether similar or divergent pathways mediate atrial natriuretic factor (ANF) induction in neonatal and hypertrophied adult ventricular myocardium, and to assess whether studies using an in vitro model system of hypertrophy have fidelity to the in vivo context during pressure overload hypertrophy, we generated transgenic mice which harbor either 638 or 3,003 bp of the rat ANF 5' flanking region ligated upstream from a luciferase reporter. Luciferase activity in the ventricles of day 1 transgenic neonates was 824-fold higher than the levels expressed in the ventricles of adult mice. Adult mice expressed the luciferase reporter in an appropriate tissue-specific manner. Transverse aortic constriction of adult mice harboring ANF reporter transgenes demonstrated no significant increase in reporter activity in the ventricle. These findings demonstrate that distinct regions of the ANF 5'-flanking region are required for inducible expression of the ANF gene in the hypertrophic adult ventricle compared with those required for atrial-specific and developmentally appropriate expression in the intact neonatal heart. Furthermore, the cis regulatory elements necessary for induction of ANF expression in endothelin-1 or $\alpha_{1}$-adrenergically stimulated cultured neonatal ventricular myocytes are not sufficient for induction in the in vivo context of pressure overload hypertrophy. (J. Clin. Invest. 1995. 96:1311-1318.) Key words: atrial natriuretic factor • hypertrophy, left ventricular • alpha-1 adrenergic receptors $\cdot$ gene expression $\cdot$ endothelin
\end{abstract}

\section{Introduction}

In response to a variety of mechanical, hormonal, and genetic stimuli, the heart adapts to increased work loads through the activation of a hypertrophic response in the ventricular myocardium. This myocardial growth response is characterized by an increase in the size of individual ventricular muscle cells, the induction of a panel of cardiac contractile protein genes, and the reexpression of genes normally expressed in the embryonic

Address correspondence to Kirk U. Knowlton, M.D., Department of Medicine, 8411, University of California, San Diego, 200 West Arbor Drive, San Diego, CA 92103-8411. Phone: 619-543-7346; FAX: 619543-7354.

Received for publication 13 January 1995 and accepted in revised form 5 June 1995.

J. Clin. Invest.

(C) The American Society for Clinical Investigation, Inc.

0021-9738/95/09/1311/08 \$2.00

Volume 96, September 1995, 1311-1318 and neonatal ventricle such as atrial natriuretic factor (ANF) ${ }^{1}$ (for reviews see references 1 and 2). Upregulation of ANF gene expression is a highly conserved genetic marker of ventricular hypertrophy both in vitro and in vivo. It occurs in response to a wide variety of hypertrophic stimuli and across highly divergent species (3-14). Since the pattern of cardiac gene expression associated with ventricular hypertrophy is very similar to that observed in the embryonic heart, it has been hypothesized that similar mechanisms may mediate induction of the embryonic genes in both situations.

Previous experiments using human ANF T-antigen transgenic mice suggested that the cis elements which regulate atrialspecific expression of the ANF gene can be segregated from those which mediate its inducible expression during pressure overload hypertrophy. The $500 \mathrm{bp}$ of human ANF promoter ligated to the $\mathrm{T}$-antigen reporter in these experiments lacked potentially important putative cis elements such as CRE, AP-1, and Egr-1 consensus binding motifs located between -638 and -500 of the ANF $5^{\prime}$ flanking region (15-17). This region has been implicated in the inducible expression of the ANF-luciferase reporter in $\alpha_{1}$-adrenergic-and endothelin-1stimulated cultured neonatal rat ventricular myocytes. In addition, transgenic mice harboring the rat ANF promoter ligated upstream from a chloramphenicol acetyltransferase (CAT) reporter have shown that a $2.4-\mathrm{kb}$ fragment of the rat ANF promoter can confer both atrial-specific as well as appropriate neonatal ventricular expression of the reporter gene (40). However, the previous experiments did not directly compare neonatal expression of the transgene and its inducible expression during pressure overload. Even though a similar pattern of gene expression occurs in the intact neonatal and hypertrophic ventricle, it is critical to determine whether the mechanisms which regulate the expression of these genes in each context occur via the same or distinct pathways.

In addition to this important issue regarding embryonic gene expression in embryonic compared with adult hypertrophic ventricular myocardium, other studies have used the induction of ANF gene expression in cultured neonatal rat ventricular cells after exposure to $\alpha_{1}$-adrenergic agonists $(15,18-25)$ endothelin-1 (26-28), and other defined growth factors (29-32) as molecular markers to identify signaling pathways that mediate cardiac muscle cell hypertrophy. Some candidate signaling molecules for this adaptive cultured myocardial cell response have been identified, including $\operatorname{Ras}(18), \mathrm{G}_{\mathrm{q}}(25)$, calcium/calmodulin-dependent pathways (20), protein kinase $C(20,33)$, and MAP kinases (28). In addition, several cis regulatory elements have been identified in vitro that may mediate inducibility of

1. Abbreviations used in this paper: ANF, atrial natriuretic factor; CAT, chloramphenicol acetyltransferase; TAC, transverse aortic constriction. 
the $\operatorname{ANF}(15,16,24,26), \beta$-myosin heavy chain $(21,35)$, and skeletal $\alpha$-actin genes $(36,37)$ after $\alpha_{1}$-adrenergic and endothelin-1 stimulation.

The physiologic role of $\alpha_{1}$-adrenergic or endothelin signaling pathways in bona fide pressure overload hypertrophy is not clear. Transgenic mice that overexpress the $\alpha_{1}$-adrenergic receptor have an increase in left ventricular mass and ANF mRNA expression (38). However, there is little direct evidence that $\alpha_{1}$-adrenergic stimulation plays a significant role in pressure overload ventricular hypertrophy. It has been shown recently that an antagonist directed against endothelin, another $G_{q}$ coupled receptor, can significantly inhibit the increase in ventricular ANF mRNA that is associated with pressure overload after $7 \mathrm{~d}$ of aortic banding (39). Therefore, it is important to determine if the mechanisms which mediate induction of ANF in cultured neonatal rat ventricular myocytes after endothelin-1 or $\alpha_{1}$-adrenergic stimulation are the same as those which mediate its induction in pressure overload hypertrophy. This would have important implications with regard to molecular and positional cues which regulate the cardiac muscle gene program during growth and development. To address these questions, it is necessary to rigorously compare results from previous work in cultured neonatal ventricular cells to the intact heart during bona fide in vivo pressure overload.

Accordingly, we generated transgenic mice that express a reporter gene behind various lengths of the ANF 5' flanking region and compared neonatal reporter expression to that observed with bona fide in vivo pressure overload hypertrophy using transverse aortic constriction (TAC). For these studies, we used independent lines of transgenic mice harboring the same ANF luciferase reporter genes that are upregulated, 610-fold, in $\alpha_{1}$-adrenergic- or endothelin-1-stimulated cultured neonatal rat myocardial cell model of in vitro hypertrophy (15, 26), and the previously reported ANF CAT transgenics (40). The adult ANF reporter transgenic mice analyzed had appropriate high level atrial-specific expression of the luciferase reporter with relatively low levels in the adult ventricle. There was also a high level of expression of the luciferase reporter in the ventricles of neonatal mice. However, in contrast to the clear inducibility of these ANF luciferase reporter genes in the cultured cell models of hypertrophy, the ANF luciferase and ANF CAT reporter genes were not significantly induced in the whole animal context of pressure overload ventricular hypertrophy. This lack of inducibility was noted, even though endogenous ANF mRNA was upregulated by $>20$-fold. This is similar to the findings in the transgenic mice that harbor $500 \mathrm{bp}$ of human ANF 5 ' flanking region upstream from T-antigen (41, 42), with the exception that neonatal expression of the T-antigen was not reported.

Therefore, these experiments demonstrate for the first time that induction of an embryonic molecular marker, ANF, during pressure overload hypertrophy in the intact ventricle occurs via a distinct mechanism than that which mediates its expression in the intact neonatal ventricle. In addition, these experiments demonstrate for the first time a clear distinction between mechanisms which mediate ANF expression in the intact animal model of pressure overload hypertrophy and cultured neonatal ventricular myocytes stimulated with agonists to the $\mathrm{G}_{\mathrm{q}}$ coupled $\alpha_{1^{-}}$ adrenergic and endothelin receptors. These findings suggest that either the induction of ANF mRNA in pressure overload ventricular hypertrophy requires critical elements that lie outside 3,000 bp of the 5' flanking region of the ANF gene or that induction of ANF mRNA expression is posttranscriptionally mediated. Other regulatory elements that have been identified in the cultured cell model of ventricular hypertrophy may be necessary, but do not appear to be sufficient, to confer inducible expression of a reporter in pressure overload ventricular hypertrophy in the whole animal. Finally, these studies underscore the importance of ultimately mapping the signaling pathways that mediate the hypertrophic response in the in vivo context, which can be done in transgenic and gene-targeted mice $(42,43)$.

\section{Methods}

Identification, generation, and breeding of transgenic mice. ANF luciferase reporter genes, ANF 3003L and ANF638L, were constructed (15) by ligating a KpnI $(-3003) / S a u 3 a(+62)$ or an EcoRI $(-638) / S a u 3 a$ ( +62 ) fragment of the rat ANF 5' flanking region (44) upstream from luciferase in the promoterless luciferase vector pSVOAL $\Delta 5^{\prime}$ (45). BamHI fragments from each construct, 5.8 or $3.4 \mathrm{~kb}$, were isolated for generation of the transgenics. The ANF2400CAT reporter construct was generated by digesting pANFCAT $(40,46)$ with NdeI resulting in a construct which contains a 2.4-kb fragment of the rat ANF 5 ' flanking region upstream from the coding sequences of the prokaryotic marker gene for CAT, and $3^{\prime}$ flanking sequences of the herpes simplex virus thymidine kinase gene containing a polyadenylation signal (Fig. 1) (40).

For the ANF-luciferase constructs, the male pronucleus of fertilized eggs from superovulated C57 $\times$ C57BL/65XSJL mice were injected with 1-2 pl of DNA at a concentration of $1 \mathrm{ng} / \mu \mathrm{l}$. Injected eggs were transferred into the oviduct of pseudopregnant CD1 mice. At 4 wk of age potential founder mice were sexed, ear punched, and distal tail excised for DNA analysis. The generation of the ANF2400CAT transgenic mice was reported previously (40).

To detect transgenic mice by PCR, two unique 21-bp oligonucleotide primers specific for sequences within the luciferase cDNA were synthesized. The primers amplified a 500-bp fragment. Approximately $1 \mu \mathrm{g}$ of purified genomic tail DNA was added to a mixture containing $1 \times$ reaction buffer ( $10 \times$ : $100 \mathrm{mM}$ Tris- $\mathrm{HCl}, \mathrm{pH} 8.3,500 \mathrm{mM} \mathrm{KCl}, 15 \mathrm{mM}$ $\mathrm{MgCl}_{2}, 0.01 \%$ [wt/vol] gelatin, $200 \mu \mathrm{M}$ each of four deoxynucleotide triphosphates, and $1 \mu \mathrm{M}$ of each oligonucleotide primer). $1 \mathrm{U}$ of Taq polymerase was added to each reaction in a total volume of $50 \mu \mathrm{l}$. A $50-100-\mu 1$ mineral oil overlay was added to prevent evaporation and loss of the reaction mixture. The samples were subjected to 30 cycles of amplification in a thermocycler according to the following program: denaturation at $94^{\circ} \mathrm{C}$ for $1 \mathrm{~min}$ followed by a 1-min annealing step at $57^{\circ} \mathrm{C}$; polymerization at $72^{\circ} \mathrm{C}$ for $2 \mathrm{~min}$; an extension period of $7 \mathrm{~min}$ at $72^{\circ} \mathrm{C}$ at the end of the 30th cycle. After amplification, $15 \mu \mathrm{l}$ of reaction mixture was electrophoresed on a $1 \%$ agarose gel at $100 \mathrm{~V}$ for $1 \mathrm{~h}$. Mice positive for the transgene were identified by the presence of a PCR product of $500 \mathrm{bp}$ on the gel.

Microsurgical techniques. 8-30-wk adult transgenic mice were anesthetized with a mixture of ketamine $(100 \mathrm{mg} / \mathrm{kg}$; intraperitoneal injection), xylazine ( $5 \mathrm{mg} / \mathrm{kg}$; intraperitoneal injection), and morphine $(2.5$ $\mathrm{mg} / \mathrm{kg}$; intraperitoneal injection) as described previously $(42,43)$. Under a dissecting microscope (model ZDX-80; Scope Instruments, San Diego, CA), animals were placed in the supine position and a midline cervical incision was made to expose the trachea. After successful endotracheal intubation, the cannula was connected to a volume cycled rodent ventilator (Harvard Apparatus, Inc., South Natick, MA) with a tidal volume of $0.2 \mathrm{ml}$ and respiratory rate of $110 / \mathrm{min}$. The chest cavity was entered in the second intercostal space at the left upper sternal border through a small incision, and TAC was performed by tying a 7-0 nylon suture ligature against a 27 -gauge needle to yield a narrowing $0.4 \mathrm{~mm}$ in diameter when the needle was removed and a reproducible constriction of $65-70 \%$ (42). The pneumothorax was evacuated, and the animals were extubated and allowed to recover.

Northern blotting. Total RNA was isolated from whole heart cells by a guanidine $\mathrm{HCl}$ technique (47). Northern analyses were performed, 


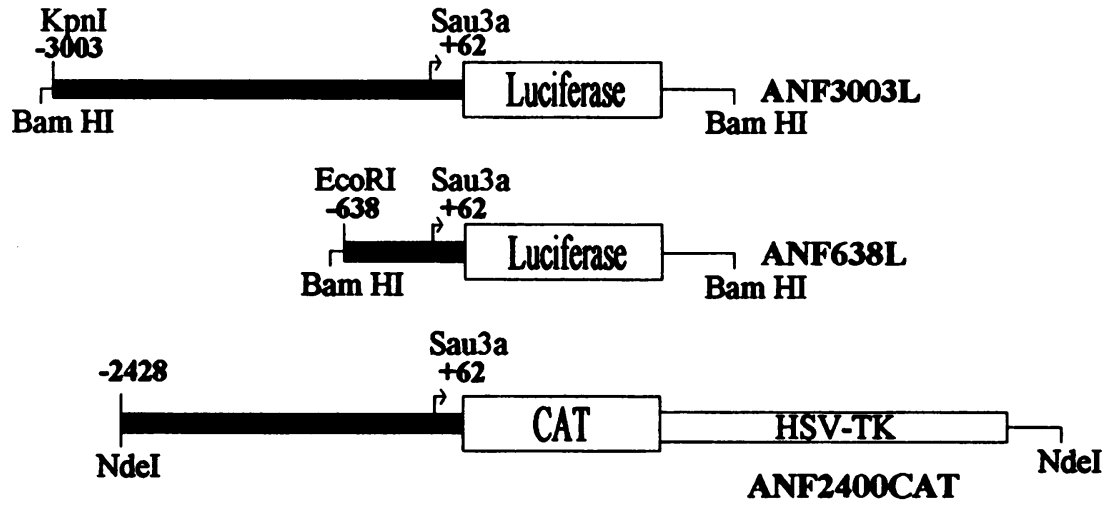

Figure 1. Structure of rat ANF reporter constructs used to generate transgenic mice. Either a 3,003or a 638-bp fragment of the rat ANF 5' flanking region was ligated into the promoterless luciferase expression vector $\mathrm{pSV0AL} \Delta 5^{\prime}(45)$. A $5.8-\mathrm{kb}$ $\mathrm{BamH1}$ fragment was isolated for generation of the ANF3003L transgenic mice, and a 3.4-kb fragment for the ANF638L mice. The ANF 2400CAT reporter construct was generated by digesting the previously described pANF-CAT $(40,46)$ with Nde1, and isolating the 5.2-kb fragment. The rat ANF 5' flanking region is depicted by the hatched bars. Restriction sites used to clone and isolate the fragments are shown. as described previously with minor modifications (15). Briefly, the RNA was size-fractionated by $1 \%$ agarose gel electrophoresis, transferred to nylon membranes by electroblotting, and hybridized with an ANF cDNA probe which was labeled with ${ }^{32} \mathrm{P}$ by random priming and was washed under appropriate conditions of stringency.

Luciferase and CAT assays. Positive transgenic mice were killed and tissues were isolated under a dissecting microscope and placed immediately in liquid nitrogen. Various muscle and nonmuscle tissues were removed from adult mice including the atria, ventricles, kidney, lung, spleen, liver, skeletal muscle (gastrocnemius), uterus, cerebral cortex, and hypothalamus. From neonatal mice the atria and ventricles were removed without separating the right and left chambers. Crosscontamination of ventricular samples with atrial tissue was avoided by discarding the basal third of the ventricle and using only the apical regions in luciferase assays. Cardiac chamber weights were obtained in adult animals (43)

Tissue extracts were prepared by homogenization in $100 \mathrm{mM}$ potassium phosphate, $\mathrm{pH} 7.4,1 \mathrm{mM}$ dithiothreitol, and $0.1 \%$ Triton X-100. Cell debris was pelleted by microcentrifugation at $4^{\circ} \mathrm{C}$ for $20 \mathrm{~min}$. The supernatant was stored at $-70^{\circ} \mathrm{C}$ until assay. A $10-\mu 1$ sample of extract was added to $100 \mu \mathrm{l}$ of KTME ( $100 \mathrm{mM}$ Tricine, $\mathrm{pH} 7.8,10 \mathrm{mM}$ $\mathrm{MgSO}_{4}, 2 \mathrm{mM}$ EDTA) containing $2 \mathrm{mM}$ ATP and $10 \mathrm{mM}$ luciferin. Peak light emission was recorded in duplicate by a luminometer (Autolumat LB 953; Berthold, Inc.). Tissue luciferase values were normalized for protein concentration assayed by the method of Bradford (48). CAT assays were performed using previously described techniques (49).

In vivo intramyocardial injection. In separate experiments, in vivo intramyocardial injection of DNA was used, using a technique similar to those described previously (50-53). After intubation of the mice for mechanical ventilation, the ventricular apex was identified through a thoracotomy in the fourth intercostal space. A mixture containing 2.5 $\mu \mathrm{g}$ of ANF638L and $2.5 \mu \mathrm{g}$ of RSV-CAT in $5 \mu \mathrm{l}$ of $0.9 \%$ saline was injected into the ventricular apex before transverse aortic constriction. The injection solution contained $0.1 \%$ trypan blue to allow localization of the intramyocardial injection to the left ventricular apex. After both intramyocardial injection and TAC $(n=10)$, the chest was closed and the pneumothorax was evacuated. Sham-operated animals $(n=7)$ underwent a similar procedure except for TAC. The mice were allowed to recover and the experiments were terminated $7 \mathrm{~d}$ later. Hearts were excised, weighed, and frozen in liquid nitrogen as described before. Protein extracts of the ventricles were used to quantitate luciferase and CAT activity. Tissue luciferase levels were normalized to CAT activity that was determined using an ELISA assay (Boehringer Mannheim Corp., Indianapolis, IN).

\section{Results}

Characterization of ANF luciferase transgenes. To determine if the 638-bp ANF 5' flanking region is capable of conferring developmentally appropriate expression of the ANF luciferase fusion gene in the embryonic ventricular myocardium, as well as to evaluate its ability to confer inducible expression during pressure overload hypertrophy in the in vivo context, two ANF luciferase fusion gene constructs were used for the generation of transgenic mice, a 638-bp ANF promoter luciferase fusion gene (ANF638L) and a 3,003-bp ANF promoter luciferase fusion gene (ANF3003L) (Fig. 1). Each one of these promoter fragments has been shown previously to display 6-10-fold inducible expression with endothelin-1 or $\alpha_{1}$-adrenergic stimulation in cultured neonatal ventricular myocytes $(15,26)$, suggesting that the endothelin- 1 and $\alpha_{1}$-adrenergic inducible regulatory elements are predominantly localized within the 638-bp promoter fragment. Two independent lines were generated which harbored the ANF638L luciferase fusion gene and which transmitted this to their progeny. A single line of ANF3003L mice was generated as a point of comparison.

ANF luciferase transgenic mice display atrial-specific expression in the adult heart. As displayed in Fig. 2, both the ANF638L and the ANF3003L transgenic mice expressed luciferase in an atrial-specific manner in the adult heart. High level expression was observed in both the left and right atrium with little expression in the ventricles. The ratio of expression between the atrium and ventricle varied from 13 to 1,100 in the three lines. In addition, in the mice harboring constructs driven by the 3,003-bp ANF promoter fragment, there was detectable expression in the brain, which is consistent with previous reports of the expression of the atrial natriuretic peptide in the subset of neuroendocrine tissues (54). Noncardiac muscle tissues, including skeletal muscle and uterus, had negligible expression of the reporter activity in any of the three independent lines, while other nonmuscle organs (kidney, lung, spleen, and liver) had luciferase activity at background levels. Thus, it is apparent that both the 3,003- and 638-bp fragments can confer appropriate atrial-specific expression in the adult mouse myocardium.

ANF luciferase transgenic mice display developmentally appropriate expression in ventricular myocardium. Previous studies have documented that ventricular myocardium expresses relatively high levels of ANF during embryonic development and in the neonatal period (55-59). Shortly after birth, the expression of the ANF gene in the ventricle is downregulated, resulting in restricted expression of the ANF gene primarily to the atria. While ANF luciferase expression in the transgenic mice is restricted to the atrial chamber in the adult myocardium, consistent with previous studies $(40,41)$, it is not clear whether 638 bp of the rat ANF 5' flanking region would confer developmentally appropriate expression of the ANF luciferase fusion 


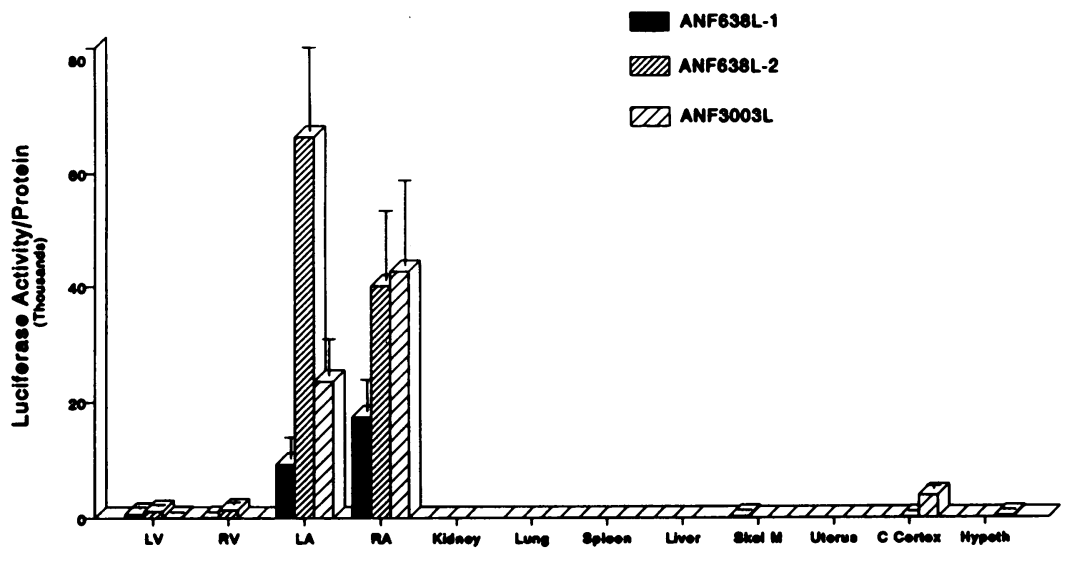

Figure 2. High level atrial expression of the luciferase reporter in adult ANF luciferase transgenic mice. Luciferase activity normalized to total protein is shown for the left ventricle $(L V)$, right ventricle $(R V)$, left atrium $(L A)$, right atrium $(R A)$, kidney, spleen, liver, skeletal muscle (Skel M), uterus, cerebral cortex (C Cortex), and hypothalamus (Hypoth) for each of the three ANF luciferase transgenic lines. There is a 131,100 -fold higher luciferase activity in the atria than in the ventricles. Luciferase activity was detected in the cerebral cortex and hypothalamus of two transgenic lines. Luciferase expression above background level was detected in skeletal muscle in one transgenic line. Data are shown as mean \pm SE. $(n=7-10$ for each data point from cardiac tissue, and $n=2-7$ for each data point from noncardiac tissue). gene in the neonatal ventricle, as is seen with the endogenous ANF gene. If such were the case, one would expect expression of the ANF transgene in the embryonic ventricle and evidence of downregulation of the reporter in the adult ventricle. To directly assess this question, several transgenic neonatal mice harboring the ANF luciferase transgene were analyzed for the expression of the luciferase reporter gene in the neonatal and adult ventricular chambers. As noted in Fig. 3, both the 3,003and the 638-bp ANF promoter fragments were capable of directing 8-24-fold higher levels of expression of the luciferase reporter gene in the neonatal ventricle than in the adult ventricle. The relative luciferase activity in day 1 neonates compared with the adults is similar to the relative levels of ANF mRNA and irANF protein in neonatal ventricles (58). These studies document that both the 3,003- and 638-bp ANF promoter fragments are not only capable of conferring atrial-specific expression in the adult myocardium but also confer appropriate neonatal expression of the ANF gene in the newborn ventricle, followed by its subsequent downregulation in the adult ventricle. Similar results have been reported in mice harboring $2,400 \mathrm{bp}$ of the rat ANF 5' flanking region ligated upstream from the CAT reporter (40).

ANF luciferase and ANF CAT transgenic mice lack inducible expression of reporter activity with pressure overload ventricular hypertrophy. The ability of the 3,003-, 2,400-, and 638bp rat ANF 5' flanking regions to confer appropriate high level neonatal expression of ANF reporter fusion genes in the neonatal ventricle suggests that these same segments of the ANF 5' flanking region might also confer inducible expression of the reporter during pressure overload ventricular hypertrophy in the adult murine ventricle. To evaluate this hypothesis, TAC was performed in the ANF luciferase and ANF CAT transgenic mice (42). Despite a significant increase in left ventricular mass (Table I) and ANF mRNA $7 \mathrm{~d}$ after TAC, there was no significant induction of reporter activity in the left ventricle (Fig. 4 $A$ ). This result was similar in all four lines harboring ANF reporter fusion genes. Luciferase activity was tested in one line of mice (ANF 638L-1) $4 \mathrm{~d}$ after aortic constriction with no significant increase in the luciferase levels over sham-operated mice (data not shown). To ensure that the lack of inducibility was reproducible, 5-20 animals were evaluated in each group. To confirm that the lack of inducible expression of the transgene was not reporter dependent, we examined the previously characterized lines of mice harboring the ANF2400CAT transgene, which have been shown to have atrial-specific expression of the CAT reporter and high level CAT activity in the neonatal ventricle (40). Similar to the results observed in mice harboring the ANF luciferase fusion genes, the ANF CAT transgenic mice did not have a statistically significant increase in expression of the CAT reporter gene, $7 \mathrm{~d}$ after aortic constriction (Fig. 4, $A$ $B)$, in spite of the marked increase in endogenous ANF mRNA (Fig. $4 C$ ).

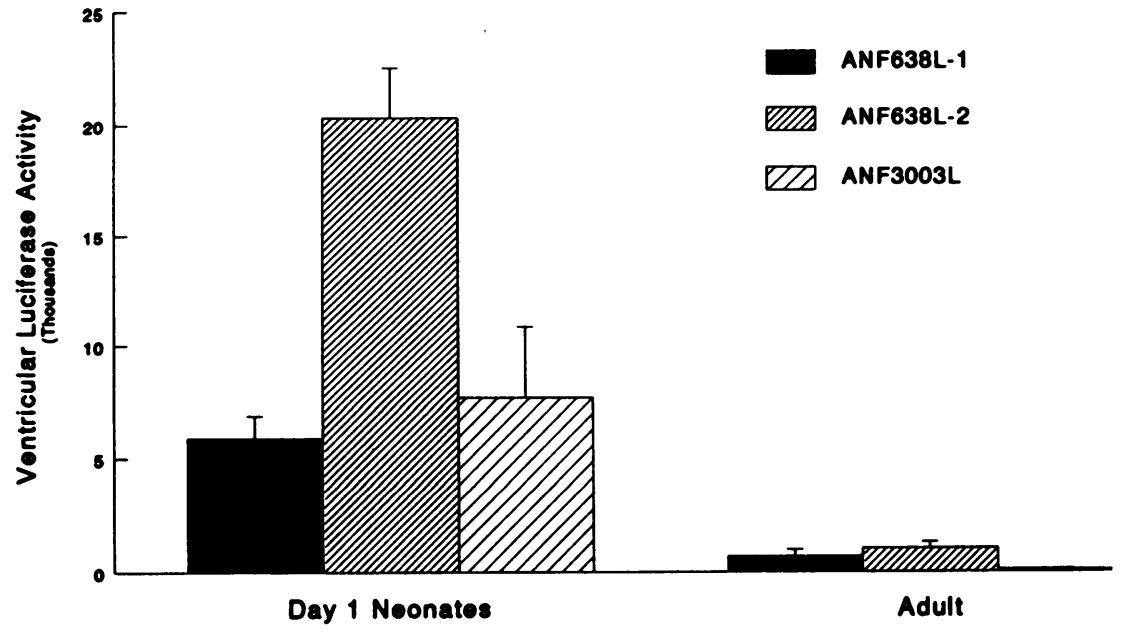

1314
Figure 3. High level transgene expression in the ventricles of day 1 neonatal mice. Ventricular chambers were dissected free of atrial tissue in day 1 neonatal transgenic mice. Combined left and right ventricular protein extracts were analyzed from neonates for luciferase activity and total protein. Ventricular luciferase activity normalized to total protein is 8-, 17-, and 124-fold higher in the neonatal ventricle than in the adult left ventricle in lines ANF638L-1, ANF638L-2, and ANF3003L, respectively. Data are expressed as mean \pm SE, $n=6-14, P<0.05$ for neonatal versus adult in each transgenic line. 
Table I. Characteristics of Sham and Pressure-overloaded ANF Luciferase Transgenic Mice with Cardiac Chamber Weights

\begin{tabular}{lccc}
\hline & Sham & TAC & $P$ value \\
\hline$n \quad \begin{array}{ccc}\text { Body weight pre-op } \\
\text { (grams) }\end{array}$ & 25 & 47 & \\
$\begin{array}{c}\text { Body weight at killing } \\
\text { (grams) }\end{array}$ & $25.9 \pm 0.94$ & $24.9 \pm 0.53$ & NS \\
LV wt. (mg) & $26.0 \pm 0.92$ & $23.4 \pm 0.47$ & 0.007 \\
RV wt. (mg) & $95 \pm 5.1$ & $116 \pm 4.1$ & 0.003 \\
LA wt. (mg) & $24 \pm 1.2$ & $21 \pm 0.6$ & 0.015 \\
RA wt. (mg) & $3.9 \pm 0.2$ & $3.6 \pm 0.2$ & NS \\
Ratios (grams/100 & $4.7 \pm 0.5$ & $3.8 \pm 0.2$ & 0.016 \\
$\quad$ grams) & & & \\
LV/BW & & & \\
RV/BW & $0.36 \pm 0.02$ & $0.46 \pm 0.01$ & $<0.0001$ \\
LA/BW & $0.09 \pm 0.003$ & $0.09 \pm 0.002$ & NS \\
RA/BW & $0.015 \pm 0.001$ & $0.021 \pm 0.001$ & 0.0003 \\
& $0.018 \pm 0.002$ & $0.015 \pm 0.001$ & NS \\
\end{tabular}

Values are mean \pm SE. $L V$, left ventricle; $R V$, right ventricle; $L A$, left atrium; $R A$, right atrium; $B W$, body weight.

To further document that this lack of inducibility was not an artifact of the transgenic system, separate experiments were performed where the ANF638L construct was coinjected with RSVCAT into the left ventricle before aortic constriction. Despite the significant increase in heart weight/body weight ratio obtained with pressure overload, no increase in luciferase activity (normalized to CAT activity) could be detected (Fig. 5).

Taken together, these studies provide compelling evidence that the induction of ANF expression in pressure overload ven- tricular hypertrophy may be mediated via distinct mechanisms than those responsible for the high level expression of ANF in the neonatal ventricle. In addition, the cis elements that mediate inducible expression in pressure overload hypertrophy are clearly distinct from those that can stimulate ANF expression in endothelin-1 or $\alpha_{1}$-adrenergically stimulated cultured ventricular myocytes. The induction of ANF mRNA in pressure overload ventricular hypertrophy may be mediated by cis regulatory elements that lie outside $638,2,400$, or 3,003 bp of the rat ANF 5 ' flanking region or the induction may be posttranscriptionally mediated.

\section{Discussion}

Divergent pathways mediate the inducible expression of the ANF gene in the neonatal and hypertrophic ventricular myocardium. One of the central features of ventricular hypertrophy is the activation of an embryonic program of gene expression. During embryonic development, the ANF gene is expressed in both the atrial and ventricular chambers. Shortly after birth, the ANF gene is downregulated in the ventricular compartment, resulting in the atrial-specific expression of the ANF gene in the adult myocardium. In response to pressure overload, the ANF gene is rapidly upregulated in the hypertrophied ventricle. Since induction of ANF expression occurs in response to diverse hypertrophic stimuli in all mammalian species thus far examined, ANF has become one of the most thoroughly studied genetic markers of the hypertrophic response. The activation of this embryonic marker during the course of hypertrophy has led to the suggestion that the mechanisms which mediate the inducibility of the ANF gene during hypertrophy might be similar or largely overlapping with the pathways which activate its expression during the course of ventricular chamber develop-
A
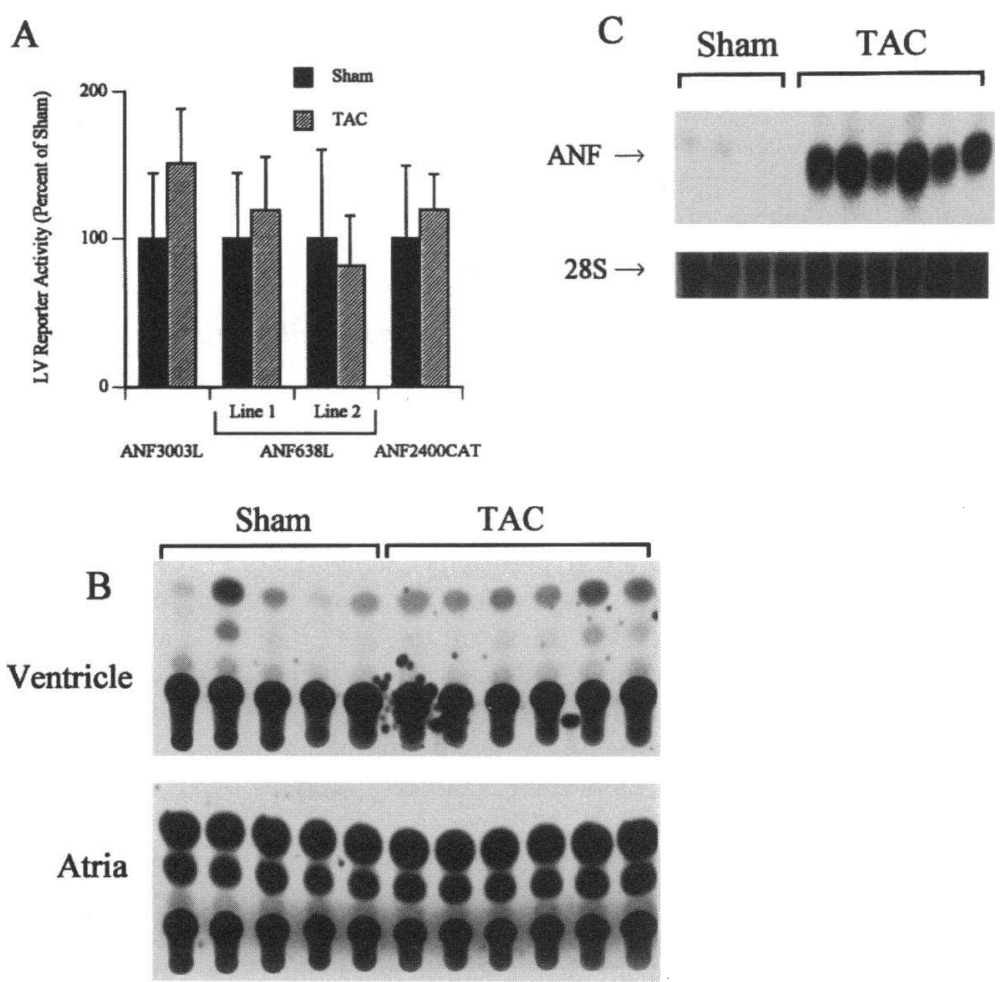

Figure 4. ANF transgene reporter activity in pressure overload ventricular hypertrophy. (A) Protein extracts from the left ventricle of pressure-overloaded (TAC) and sham-operated transgenic mice were analyzed for luciferase or CAT reporter activity. The reporter activity is normalized to total protein. The CAT activity was quantitated as percentage acetylated using an Ambus scanner. There is no significant increase in transgene reporter activity for any of the four transgenic lines. Data are shown as a percentage of left ventricular reporter activity in sham-operated animals, mean \pm SE, $n=5-20, P=0.407,0.501,0.778$, and 0.721 for each transgenic line from left to right, respectively. $(B)$ CAT activity in left ventricle (top) and atria (bottom) of sham and pressure-overloaded (TAC) adult transgenic mice. $100 \mu \mathrm{g}$ of left ventricle or $1 \mu \mathrm{g}$ of atrial protein extracts was examined for CAT activity. (C) A Northern blot using $20 \mu \mathrm{g}$ of total RNA from the left ventricles of sham and pressure-overloaded (TAC) transgenic mice was probed for ANF mRNA using a rat ANF cDNA probe. Methylene blue staining of 28S ribosomal RNA is shown below. These samples are from portions of 10 out of 11 of the same ventricles used to analyze CAT activity shown in $B$. Similar results were obtained when ANF luciferase transgenic mice were analyzed for ANF mRNA. 


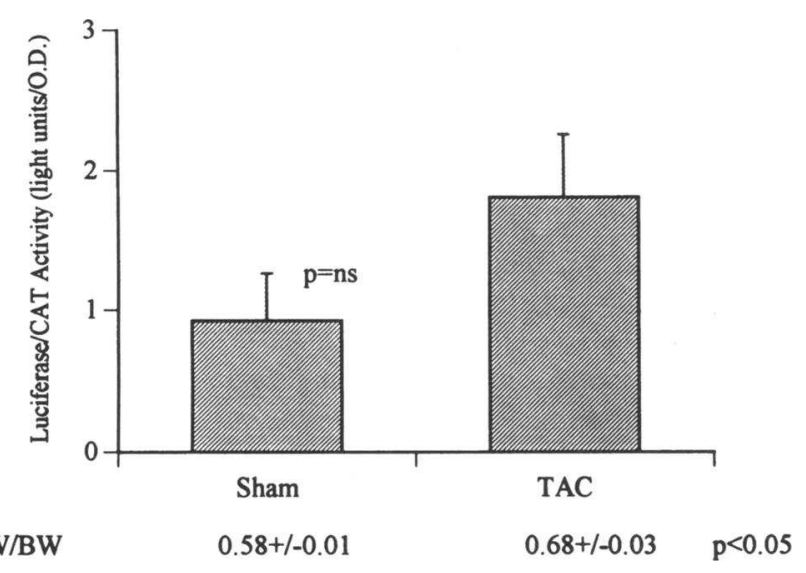

Figure 5. Lack of induction of ANF638L with transverse aortic constriction after intramyocardial injection of DNA. $2.5 \mu \mathrm{g}$ of ANF638L plasmid DNA and $2.5 \mu \mathrm{g}$ of RSVCAT plasmid DNA in a 5- $\mu \mathrm{l}$ volume was injected directly into the left ventricular apex of adult mice immediately before sham procedure (Sham, $n=7$ ) or transverse aortic constriction (TAC, $n=10) .7 \mathrm{~d}$ after aortic constriction, hearts were harvested, weighed, and assayed for luciferase and CAT activity as described. A significant increase in heart weight to body weight $(H W / B W)$ ratio with TAC occurred without a significant increase in luciferase reporter activity. Data are mean $\pm S E$.

ment. The upregulation of the ANF gene during stimulation with peptide-derived growth factors which are important for cardiac development (e.g., endothelin-1, thrombin, TGF $\beta$, FGF, and angiotensin II) has lent further support to this view (26, $29,31,60)$. However, a critical evaluation of whether shared or divergent pathways mediate the induction of the ANF gene during development and hypertrophy requires whole animal model systems in which to unequivocally monitor the regulated expression of the ANF gene during in vivo pressure overload and in the normal context of cardiac development.

While previous experiments using transgenic mice have shown that the mechanisms which mediate atrial-specific expression of ANF could be segregated from those which mediate inducible expression, our study provides the first compelling evidence that different pathways mediate the expression of the ANF gene in neonatal ventricular myocardium compared with the hypertrophic adult ventricular myocardium. Independent lines of ANF luciferase and ANF CAT transgenic mice display appropriate neonatal ventricular expression of the ANF reporter gene which is downregulated towards negligible levels in the adult ventricle. However, in a well characterized mouse model of in vivo pressure overload hypertrophy, there is a marked induction of the endogenous ANF mRNA levels but no statistically significant increase in luciferase or CAT reporter activity. Furthermore, the lack of inducibility was observed with intramyocardial injection of DNA, suggesting that this lack of inducibility is not limited to transgenic models. The mechanisms which underlie these divergent pathways are unclear. However, the possibility exists that the pathways required for the activation of expression of the ANF gene in the context of ventricular development are necessary, but perhaps not sufficient, to reactivate the expression of the ANF gene in the setting of ventricular hypertrophy. In this manner, an additional molecular switch might be required for the induction of this embryonic marker in adult ventricular muscle cell context.
Cis regulatory sequences which mediate inducible expression are not found within a 3,003-bp 5' flanking region of the ANF promoter region. Previous experiments demonstrate that $500 \mathrm{bp}$ of the human ANF $5^{\prime}$ flanking region could not confer inducible expression to the ANF T-antigen after pressure overload. However, this construct lacked potentially important putative cis regulatory elements located between -500 and -638 that had been implicated in induction of ANF expression in cultured neonatal rat ventricular myocytes stimulated with the $\mathrm{G}_{\mathrm{q}}$ receptor agonists endothelin, $\alpha_{1}$-adrenergic, and thrombin receptors $(15,16,26,31)$. Several model systems of cultured neonatal rat ventricular myocytes have been extensively characterized. Stimulated cultured myocytes acquire several structural, morphological, and genetic markers of hypertrophy (including the upregulation of the ANF gene). In addition to its ability to confer inducible expression in cultured neonatal myocytes, the 638-bp region is sufficient for high level ANF expression in neonatal ventricles in vivo. Therefore, it was hypothesized that the 638-bp ANF promoter fragment might confer inducibility in the in vivo context after pressure overload hypertrophy. However, neither a 3,003-, 2,400-, nor a 638-bp ANF promoter fragment was sufficient to confer inducible expression to luciferase or CAT reporter genes. The basis for this phenomenon is unclear. However, the possibility exists that intragenic sequences, cis regulatory elements which lie further upstream, or posttranscriptional mechanisms may be required for the response. The present experiments cannot exclude the possibility of species-specific differences in trans-acting factors or cisacting sequences of these otherwise homologous rodent genes.

Of particular relevance may be the studies of the developmental regulation of the globin genes by cis sequences which lie at considerable distance from the transcription initiation site $(>30 \mathrm{~kb})(61)$. These locus control regions act in concert with elements which lie in the proximal promoter region to activate the developmentally appropriate expression of the globin gene family. A number of distinct cis regulatory elements have been found to mediate the inducibility of the ANF gene during in vitro hypertrophy of neonatal rat ventricular cells $(17,62)$. As studies in transgenic animals have been critical in defining the role of locus control regions in globin gene regulation, they may also prove valuable in localizing the elements required for induction of the ANF gene during the hypertrophic response and defining their interaction with more proximal promoter elements.

Discordance between results on inducible expression of the ANF gene in in vitro versus in vivo models of myocardial cell hypertrophy. Using an in vitro model system of hypertrophy in cultured neonatal rat ventricular muscle cells, a number of well defined growth factors, stretch, and hormonal stimuli have been identified which can elicit morphological, biochemical, and genetic markers of the hypertrophic phenotype (63-70). A combination of cotransfection and microinjection approaches has identified important roles for ras (18), $\mathrm{G}_{\mathrm{q}}(25)$, and protein kinase $\mathrm{C}$-dependent pathways $(21,33)$ in the transduction of signals to the nucleus, which eventually results in the upregulation of constitutively expressed contractile protein genes (e.g., MLC-2v) and embryonic markers, such as ANF, $\beta$-myosin heavy chain, and $\alpha$-skeletal actin. The utility of this system for identifying important cardiac signaling molecules has been demonstrated recently, as transgenic mice which express oncogenic ras in the ventricular chamber display structural, physiological, and genetic markers of hypertrophy (71). Thus, in vitro 
models of hypertrophy may be valuable for identifying proximal signaling pathways that are important in in vivo model systems. However, whether the more distal nuclear signaling pathways for the induction of the cardiac muscle gene program would also be similar in the in vitro and in vivo context is unclear.

A stretch-activated cultured cell model of ventricular hypertrophy has characteristics that are consistent with our findings in pressure overload hypertrophy. Stretch of cultured neonatal rat ventricular myocytes results in an increase in the embryonic program of endogenous gene expression including ANF and $\beta$ myosin heavy chain. However, neither 3,412 bp of the ANF nor $628 \mathrm{bp}$ of the $\beta$-myosin heavy chain $5^{\prime}$ flanking region are sufficient to induce expression of transfected reporter genes (72). In an electrically paced model of cultured neonatal ventricular cell hypertrophy there is an increase in cell size and an increase in endogenous ANF mRNA levels. Unlike the stretchactivated model of hypertrophy, the 638-bp $5^{\prime}$ flanking region of the ANF gene is capable of conferring inducible expression to a reporter gene (73).

These results in combination with the results of our study emphasize the importance of critically evaluating the role of various proximal stimuli and their downstream signaling pathways which have been identified in in vitro model systems with the in vivo context after the delivery of physiologically appropriate stimuli $(43,66)$. Undoubtedly, in vitro model systems will continue to be valuable in identifying candidate regulatory factors and pathways for the activation of the hypertrophic response. However, since neonatal rat ventricular muscle cells may be more permissive than adult muscle myocardial cells for the upregulation of the embryonic gene program, additional molecular switches may be required for the activation of hypertrophy in the adult versus neonatal heart. Alternatively, the complex physiology of the hypertrophic response in vivo may be difficult to fully mimic in in vitro model systems. These results, therefore, validate the importance of evaluating signaling pathways of cardiac muscle hypertrophy in vivo using transgenic and gene-targeted animals.

\section{Acknowledgments}

This study was supported by grants from the National Institutes of Health (HL-02618 to K. U. Knowlton, HL-42467 to C. E. Seidman, HL-45069 to K. R. Chien, P01 HL-46345 to K. R. Chien and H. A. Rockman) and the American Heart Association (AHA CA-94-276 to K. U. Knowlton, AHA CA-92-300 to H. A. Rockman, Established Investigator Award to C. E. Seidman, UCSD/AHA Bugher Foundation 9102217 to K. R. Chien).

\section{References}

1. Chien, K. R., K. U. Knowlton, H. Zhu, and S. Chien. 1991. Regulation of cardiac gene expression during myocardial growth and hypertrophy: molecular studies of an adaptive physiologic response. FASEB (Fed. Am. Soc. Exp. Biol.) J. 5:3037-3046.

2. Chien, K. R., H. Zhu, K. U. Knowlton, W. Miller-Hance, M. van-Bilsen, T. X. O'Brien, and S. M. Evans. 1993. Transcriptional regulation during cardiac growth and development. Annu. Rev. Physiol. 55:77-95.

3. Izumo, S., B. Nadal-Ginard, and V. Mahdavi. 1988. Protooncogene induction and reprogramming of cardiac gene expression produced by pressure overload. Proc. Natl. Acad. Sci. USA. 85:339-343.

4. Lee, R. T., K. D. Bloch, J. M. Pfeffer, M. A. Pfeffer, E. J. Neer, and C. E. Seidman. 1988. Atrial natriuretic factor gene expression in ventricles of rats with spontaneous biventricular hypertrophy. J. Clin. Invest. 81:431-434.

5. Takemura, G., H. Fujiwara, M. Mukoyama, Y. Saito, K. Nakao, A. Kawamura, M. Ishida, M. Kida, T. Uegaito, and M. Tanaka. 1991. Expression and distribution of atrial natriuretic peptide in human hypertrophic ventricle of hyper- ensive hearts and hearts with hypertrophic cardiomyopathy. Circulation 83:181190

6. Gu, J., and L. B. McGrath. 1990. Localized endocrine conversion of ventricular cardiocytes in ventricular aneurysm. $J$. Histochem. Cytochem. 38:1659-1668.

7. Franch, H. A., R. A. Dixon, E. H. Blaine, and P. K. Siegl. 1988. Ventricular atrial natriuretic factor in the cardiomyopathic hamster model of congestive heart failure. Circ. Res. 62:31-36.

8. Edwards, B. S. D. M. Ackermann, M. E. Lee, G. S. Reeder, L. E. Wold, and J. C. Burnett, Jr. 1988. Identification of atrial natriuretic factor within ventricular tissue in hamsters and humans with congestive heart failure. J. Clin. Invest. 81:82-86.

9. Yasue, H., K. Obata, K. Okumura, M. Kurose, H. Ogawa, K. Matsuyama, M. Jougasaki, Y. Saito, K. Nakao, and H. Imura. 1989. Increased secretion of atrial natriuretic polypeptide from the left ventricle in patients with dilated cardiomyopathy. J. Clin. Invest. 83:46-51.

10. Saito, Y., K. Nakao, H. Arai, K. Nishimura, K. Okumura, K. Obata, G. Takemura, H. Fujiwara, A. Sugawara, and T. Yamada. 1989. Augmented expression of atrial natriuretic polypeptide gene in ventricle of human failing heart. $J$. Clin. Invest. 83:298-305.

11. Tsuchimochi, H., F. Kurimoto, K. Ieki, H. Koyama, F. Takaku, M. Kawana, S. Kimata, and Y. Yazaki. 1988. Atrial natriuretic peptide distribution in fetal and failed adult human hearts. Circulation. 78:920-927.

12. Fujiwara, T., H. Fujiwara, G. Takemura, M. Mukoyama, Y. Saito, K. Nakao, H. Imura, M. Nakano, and K. Baba. 1990. Expression and distribution of atrial natriuretic polypeptide in the ventricles of children with myocarditis and/ or myocardial infarction secondary to Kawasaki disease: immunohistochemical study. Am. Heart J. 120:612-618.

13. Arai, H., K,. Nakao, Y. Saito, N. Morii, A. Sugawara, T. Yamada, H. Itoh, S. Shiono, M. Mukoyama, and H. Ohkubo. 1988. Augmented expression of atrial natriuretic polypeptide gene in ventricles of spontaneously hypertensive rats (SHR) and SHR-stroke prone. Circ. Res.62:926-930.

14. Lattion, A. L., J. B. Michel, E. Arnauld, P. Corvol, and F. Soubrier. 1986. Myocardial recruitment during ANF mRNA increase with volume overload. Am. J. Physiol. 251:H890-H896.

15. Knowlton, K. U., E. Baracchini, R. S. Ross, A. N. Harris, S. A. Henderson, S. M. Evans, C. C. Glembotski, and K. R. Chien. 1991. Co-regulation of the atrial natriuretic factor and cardiac myosin light chain-2 genes during alpha-adrenergic stimulation of neonatal rat ventricular cells. Identification of cis sequences within an embryonic and a constitutive contractile protein gene which mediate inducible expression. J. Biol. Chem. 266:7759-7768.

16. Rosenzweig, A., T. D. Halazonetis, J. G. Seidman, and C. E. Seidman. 1991. Proximal regulatory domains of rat atrial natriuretic factor gene. Circulation. 84:1256-1265.

17. Harris, A. N., Y. F. Chen, and K. R. Chien. 1992. Cis sequences within the atrial natriuretic factor gene which mediate inducibility by activated ras and phenylephrine. Circulation. 86(Suppl.):I-95a. (Abstr.)

18. Thorburn, A., J. Thorburn, S. Y. Chen, S. Powers, H. E. Shubeita, J. R. Feramisco, and K. R. Chien. 1993. HRas dependent pathways can activate morphological and genetic markers of cardiac muscle cell hypertrophy. J. Biol. Chem. 268:2244-2249.

19. Knowlton, K. U., M. C. Michel, M. Itani, H. E. Shubeita, K. Ishihara, J. Heller-Brown, and K. R. Chien. 1993. The $\alpha 1 \mathrm{~A}$-adrenergic receptor subtype mediates biochemical, molecular, and morphologic features of cultured myocardial cell hypertrophy. J. Biol. Chem. 268:15374-15380.

20. Sei, C. A., C. E. Irons, A. B. Sprenkle, P. M. McDonough, J. H. Brown, and C. C. Glembotski. 1991. The $\alpha$ adrenergic stimulation of atrial natriuretic factor expression in cardiac myocytes requires calcium influx, protein kinase $C$, and calmodulin-regulated pathways. J. Biol. Chem. 266:15910-15916.

21. Kariya, K., L. R. Karns, and P. C. Simpson. 1991. Expression of a constitutively activated mutant of the beta-isozyme of protein kinase $C$ in cardiac myocytes stimulates the promoter of the beta-myosin heavy chain isogene. J. Biol. Chem. 266:10023-10026.

22. Simpson, P. C. 1989. Proto-oncogenes and cardiac hypertrophy. Annu. Rev. Physiol. 51:189-202.

23. Simpson, P. C. 1983. Norepinephrine-stimulated hypertrophy of cultured rat myocardial cells is an alpha 1 adrenergic response. J. Clin. Invest. 72:732738 .

24. Ardati, A., and M. Nemer. 1993. A nuclear pathway for alpha 1-adrenergic receptor signaling in cardiac cells. EMBO (Eur. Mol. Biol. Organ.) J. 12:5131 5139.

25. LaMorte, V. J., J. Thorburn, D. Absher, A. Spiegel, J. H. Brown, K. R. Chien, J. R. Feramisco, and K. U. Knowlton. 1994. G and Ras dependent pathways mediate hypertrophy of neonatal rat ventricular myocytes following $\alpha_{1-}$ adrenergic stimulation. J. Biol. Chem. 269:13490-13496.

26. Shubeita, H. E., P. M. McDonough, A. N. Harris, K. U. Knowlton, C. C. Glembotski, J. H. Brown, and K. R. Chien. 1990. Endothelin induction of inositol phospholipid hydrolysis, sarcomere assembly, and cardiac gene expression in ventricular myocytes. A paracrine mechanism for myocardial cell hypertrophy. $J$. Biol. Chem. 265:20555-20562.

27. McDonough, P. M., J. Heller-Brown, and C. C. Glembotski. 1993. Phenyl- 
ephrine and endothelin differentially stimulate cardiac PI hydrolysis and ANF expression. Am. J. Physiol. 264:H625-H630.

28. Bogoyevitch, M. A., P. E. Glennon, and P. H. Sugden. 1993. Endothelin1, phorbol esters and phenylephrine stimulate MAP kinase activities in ventricular cardiomyocytes. FEBS Lett. 317:271-275.

29. Schneider, M. D., W. R. McLellan, F. M. Black, and T. G. Parker. 1992. Growth factors, growth factor response elements, and the cardiac phenotype. Basic Res. Cardiol. 87(Suppl. 2):33-48.

30. Rundle, S. E., M. J. Fullerton, and J. W. Funder. 1990. Induction of ventricular morphogenesis and atrial natriuretic factor synthesis by thyroid hormone. Mol. Cell. Endocrinol. 68:163-168.

31. Glembotski, C. C., C. E. Irons, K. A. Krown, S. F. Murray, A. B. Sprenkle, and C. A. Sei. 1993. Myocardial alpha-thrombin receptor activation induces hypertrophy and increases atrial natriuretic factor gene expression. J. Biol. Chem. 268:20646-20652.

32. Argentin, S., Y. L. Sun, I. Lihrmann, T. J. Schmidt, J. Drouin, and M. Nemer. 1991. Distal cis-acting promoter sequences mediate glucocorticoid stimulation of cardiac atrial natriuretic factor gene expression. J. Biol. Chem. 266:23315-23322.

33. Shubeita, H. E., E. A. Martinson, M. Van Bilsen, K. R. Chien, and J. H. Brown. 1992. Transcriptional activation of the cardiac myosin light chain 2 and atrial natriuretic factor genes by protein kinase $\mathrm{C}$ in neonatal rat ventricular myocytes. Proc. Natl. Acad. Sci. USA. 89:1305-1309.

34. Deleted in proof

35. Waspe, L. E., C. P. Ordahl, and P. C. Simpson. 1990. The cardiac betamyosin heavy chain isogene is induced selectively in alpha 1-adrenergic receptorstimulated hypertrophy of cultured rat heart myocytes. J. Clin. Invest. 85:12061214.

36. Long, C. S., C. P. Ordahl, and P. C. Simpson. 1989. Alpha 1-adrenergic receptor stimulation of sarcomeric actin isogene transcription in hypertrophy of cultured rat heart muscle cells. J. Clin. Invest. 83:1078-1082.

37. Bishopric, N. H., and L. Kedes. 1991. Adrenergic regulation of the skeletal alpha-actin gene promoter during myocardial cell hypertrophy. Proc. Natl. Acad. Sci. USA. 88:2132-2136.

38. Milano, C. A., P., C. Dolber, H. A. Rockman, R. A. Bond, M. E. Venable, L. F. Allen, and R. J. Lefkowitz. 1994. Myocardial expression of a constitutively active alpha 1B-adrenergic receptor in transgenic mice induces cardiac hypertrophy. Proc. Natl. Acad. Sci. USA. 91:10109-10113.

39. Ito, H., M. Hiroe, Y. Hirata, H. Fujisaki, S. Adachi, H. Akimoto, Y. Ohta, and F. Marumo. 1994. Endothelin ETA receptor antagonist blocks cardiac hypertrophy provoked by hemodynamic overload. Circulation. 89:2198-2203.

40. Seidman, C. E., E. V. Schmidt, and J. G. Seidman. 1991. Cis-dominance of rat atrial natriuretic factor gene regulatory sequences in transgenic mice. Can. J. Physiol. Pharmacol. 69:1486-1492.

41. Field, L. J. 1988. Atrial natriuretic factor-SV40 T antigen transgenes produce tumors and cardiac arrhythmias in mice. Science (Wash. DC). 239:10291033.

42. Rockman, H. A., R. S. Ross, A. N. Harris, K. U. Knowlton, M. E. Steinhelper, L. J. Field, J. Ross, Jr., and K. R. Chien. 1991. Segregation of atrialspecific and inducible expression of an atrial natriuretic factor transgene in an in vivo murine model of cardiac hypertrophy. Proc. Natl. Acad. Sci. USA. 88:82778281.

43. Rockman, H. A., S. Ono, R. S. Ross, L. R. Jones, M. Karimi, V. Bhargava, J. Ross, Jr., and K. R. Chien. 1994. Molecular and physiological alterations in murine ventricular dysfunction. Proc. Natl. Acad. Sci. USA. 91:2694-2698.

44. Argentin, S., M. Nemer, J. Drouin, G. K. Scott, B. P. Kennedy, and P. L. Davies. 1984. The gene for rat atrial natriuretic factor. J. Biol. Chem. 8:45684571.

45. de Wet, J. R., K. V. Wood, M. DeLuca, D. R. Helinski, and S. Subramani 1987. Firefly luciferase gene: structure and expression in mammalian cells. Mol. Cell. Biol. 7:725-737.

46. Seidman, C. E., D. W. Wong, J. A. Jarcho, K. D. Bloch, and J. G. Seidman 1988. Cis-acting sequences that modulate atrial natriuretic factor gene expression Proc. Natl. Acad. Sci. USA. 85:4104-4108.

47. Chirgwin, J. M., A. Przybyla, R. J. MacDonald, and W. J. Rutter. 1979. Isolation of biologically active ribonucleic acid from sources enriched in ribonuclease. Biochemistry. 18:5294-5299.

48. Bradford, M. M. 1976. A rapid and sensitive method for the quantitation of microgram quantities of protein utilizing the principle of protein-dye binding. Anal. Biochem. 72:248-254.

49. Gorman, C. M., L. F. Moffat, and B. H. Howard. 1982. Recombinant genomes which express chloramphenicol acetyltransferase in mammalian cells Mol. Cell. Biol. 2:1044-1051.

50. Buttrick, P. M., M. L. Kaplan, R. N. Kitsis, and L. A. Leinwand. 1993.
Distinct behavior of cardiac myosin heavy chain gene constructs in vivo. Discordance with in vitro results. Circ. Res. 72:1211-1217.

51. Buttrick, P. M., A. Kass, R. N. Kitsis, M. L. Kaplan, and L. A. Leinwand 1992. Behavior of genes directly injected into the rat heart in vivo. Circ. Res. 70:193-198.

52. Parmacek, M. S., A. J. Vora, T. Shen, E. Barr, F. Jung, and J. M. Leiden. 1992. Identification and characterization of a cardiac-specific transcriptional regulatory element in the slow/cardiac troponin C gene. Mol. Cell. Biol. 12:19671976.

53. Lin, H., M. S. Parmacek, G. Morle, S. Bolling, and J. M. Leiden. 1990. Expression of recombinant genes in myocardium in vivo after direct injection of DNA. Circulation. 82:2217-2221.

54. Gardner, D. G., G. P. Vlasuk, J. D. Baxter, J. C. Fiddes, and J. A. Lewicki. 1987. Identification of atrial natriuretic factor gene transcripts in the central nervous system of the rat. Proc. Natl. Acad. Sci. USA. 84:2175-2179.

55. Zeller, R., K. D. Bloch, B. S. Williams, R. J. Arceci, and C. E. Seidman. 1987. Localized expression of the atrial natriuretic factor gene during cardiac embryogenesis. Genes Dev. 1:693-698.

56. Seidman, C. E., and A. Rosenzweig. 1991. Atrial natriuretic factor and related peptide hormones. Annu. Rev. Biochem. 60:229-255.

57. Gardner, D. G., B. K. Hedges, J. Wu, M. C. LaPointe, and C. F. Deschepper, 1989. Expression of the atrial natriuretic peptide gene in human fetal heart. J. Clin. Endocrinol. \& Metab. 69:729-737.

58. Wu, J. P., C. F. Deschepper, and D. G. Gardner. 1988. Perinatal expression of the atrial natriuretic factor gene in rat cardiac tissue. Am. J. Physiol. 255:E388E396.

59. Bloch, K. D., J. G. Seidman, J. D. Naftilan, J. T. Fallon, and C. E Seidman. 1986. Neonatal atria and ventricles secrete atrial natriuretic factor via tissue-specific secretory pathways. Cell. 47:695-702.

60. Sadoshimà, J., Y. Xu, H. S. Slayter, and S. Izumo. 1993. Autocrine release of angiotensin II mediates stretch-induced hypertrophy of cardiac myocytes in vitro. Cell. 75:977-984.

61. Orkin, S. H. 1990. Globin gene regulation and switching: circa 1990. Cell. 63:665-672.

62. Argentin, S., A. Ardati, S. Tremblay, I. Lihrmann, L. Robitaille, J. Drouin, and M. Nemer. 1994. Developmental stage-specific regulation of atrial natriuretic factor gene transcription in cardiac cells. Mol. Cell. Biol. 14:777-790.

63. Komuro, I., T. Kaida, Y. Shibazaki, M. Kurabayashi, Y. Katoh, E. Hoh,

F. Takaku, and Y. Yazaki. 1990. Stretching cardiac myocytes stimulates protooncogene expression. J. Biol. Chem. 265:3595-3598.

64. Komuro, I., and Y. Yazaki. 1993. Control of cardiac gene expression by mechanical stress. Annu. Rev. Physiol. 55:55-75.

65. Lee, H. R., S. A. Henderson, R. Reynolds, P. Dunnmon, D. Yuan, and K. R. Chien. 1988. Alpha 1-adrenergic stimulation of cardiac gene transcription in neonatal rat myocardial cells. Effects on myosin light chain-2 gene expression. J. Biol. Chem. 263:7352-7358.

66. Morgan, H. E. 1993. Cellular aspects of cardiac failure. Circulation. 87:IV4-IV6.

67. Morgan, H. E., and K. M. Baker. 1991. Cardiac hypertrophy. Mechanical, neural, and endocrine dependence. Circulation. 83:13-25.

68. Zhu, H., A. V. Garcia, R. S. Ross, S. M. Evans, and K. R. Chien. 1991. A conserved 28-base-pair element (HF-1) in the rat cardiac myosin light-chain-2 gene confers cardiac-specific and alpha-adrenergic-inducible expression in cultured neonatal rat myocardial cells. Mol. Cell. Biol. 11:2273-2281.

69. Iwaki, K., V. P. Sukhatme, H. E. Shubeita, and K. R. Chien. 1990. Alphaand beta-adrenergic stimulation induces distinct patterns of immediate early gene expression in neonatal rat myocardial cells. fos/jun expression is associated with sarcomere assembly; Egr-1 induction is primarily an alpha 1-mediated response. J. Biol. Chem. 265:13809-13817.

70. Rockman, H. A., S. P. Wachhorst, L. Mao, and J. Ross, Jr. 1994. ANG II-receptor blockade prevents ventricular hypertrophy and ANF gene expression with pressure overload in mice. Am. J. Physiol. 267:H1-H8.

71. Hunter, J., N. Tanaka, H. A. Rockman, J. Ross, Jr., and K. R. Chien. 1995. Ventricular expression of a MLC-2v-Ras fusion gene induces cardiac hypertrophy and selective diastolic dysfunction in transgenic mice. J. Biol. Chem. In press.

72. Sadoshima, J., L. Jahn, T. Takahashi, T. J. Kulik, and S. Izumo. 1992. Molecular characterization of the stretch-induced adaptation of cultured cardiac cells. An in vitro model of load-induced cardiac hypertrophy. J. Biol. Chem. 267:10551-10560.

73. McDonough, P. M., and C. C. Glembotski. 1992. Induction of atrial natriuretic factor and myosin light chain-2 gene expression in cultured ventricular myocytes by electrical stimulation of contraction. J. Biol. Chem. 267:1166511668. 